\title{
Biostimulation Effects and Temperature Variation in Stimulated Dielectric Substance (Diabetic Blood Comparable to Non-Diabetic Blood) Based on the Specific Absorption Rate (SAR) in Laser Therapy
}

\author{
Sylvester J. Gemanam ${ }^{\mathrm{a}, \mathrm{b}}$, Nursakinah Suardi ${ }^{\mathrm{a}}$, Barnabas A. Ikyo ${ }^{\mathrm{b}}$, Samson Damilola Oluwafemi ${ }^{\mathrm{a}}$, \\ Terver Daniel ${ }^{\mathrm{b}, *}$, Samuel T. Kungur ${ }^{\mathrm{c}}$ \\ ${ }^{a}$ School of Physics, Universiti Sains Malaysia (USM), Pulau Pinang, Penang, 11800, Malaysia \\ ${ }^{b}$ Department of Physics, Faculty of Science, Benue State University, Makurdi, 102119, Nigeria \\ ${ }^{c}$ Department of Physics, College of Education, Katsina-Ala, Benue State, Nigeria
}

\begin{abstract}
Human blood exposed to irradiation absorbs electromagnetic energy which consequently effect temperature variation. The evaluation of Specific Absorption Rate (SAR) of human blood helps to ascertain the values for optimum laser power, time, and temperature variation for fair therapy to avoid blood-irradiation pollution but to enhance its rheological properties when using lasers. Prior knowledge of blood SAR evaluating its dielectric properties is significant, but this is under investigation. We investigate the appropriate SAR threshold value as affected by temperature variation using fundamental blood dielectric parameters to optimize the effect of low-level laser therapy based on physiological and morphological changes of the stimulated diabetic blood. Studies were carried out with Agilent $4294 \mathrm{~A}$ impedance analyser at frequencies $(40 \mathrm{~Hz}-30 \mathrm{MHz})$ and designed cells (cuvettes) comprises of electrodes were used in the pre- and post-irradiations measurements. At different laser power outputs, blood samples were subjected to various irradiation durations using portable laser diode-pumped solid state of wavelength $532 \mathrm{~nm}$. Results showed laser at low energy is capable of moderating morphologically the proportion of abnormal diabetic red blood cells. Hence, there is a significant effect using a laser at low energy, as non-medicinal therapy in controlling diabetic health conditions. The positive biostimulation effects on the irradiated diabetic blood occurred within absorbance threshold SAR values range of $0.140 \leq 0.695 \mathrm{~W} / \mathrm{kg}$ and average temperatures range of $24.2 \leq 28.0^{\circ} \mathrm{C}$ before blood saturation absorbance peak. There is morphological stimulation at a laser power of $50 \mathrm{~mW}$ for an exposure time of 10-15 minutes and $60 \mathrm{~mW}$ for 5-10 minutes of laser therapy that demonstrates better blood rejuvenated conditions. This occurred within the threshold SAR of $0.140 \leq 0.695 \mathrm{~W} / \mathrm{kg}$ and average temperatures range of $24.2 \leq 28.0^{\circ} \mathrm{C}$. Therefore, the diabetic blood irradiated using laser output powers of 70 and $80 \mathrm{~mW}$ during exposure durations of 5,10,15 and 20 minutes rather bio-inhibits positive blood stimulation which has resulted to crenation due to excessive irradiation.
\end{abstract}

DOI:10.46481/jnsps.2021.182

Keywords: Dielectric properties, specific absorption rates, diabetic blood, low-level laser therapy, impedance, diabetic blood.

Article History :

Received: 24 March 2021

Received in revised form: 15 April 2021

Accepted for publication: 24 April 2021

Published: 29 May 2021

(C)2021 Journal of the Nigerian Society of Physical Sciences. All rights reserved. Communicated by: W. A. Yahya 


\section{Introduction}

Laser technology has significantly impacted in medicine and medical research studies due to its quick advancement and acceptance of non-invasive treatment techniques [1]. The applications yield an all-encompassing range of biomedical fields. This includes its attempts in the treatment of cancer, diabetes, and other diseases. The low-level laser-induced therapy has demonstrated to be minimally invasive and an encouraging surgical technique in diabetes treatment, tumour treatment in brain, liver, lung and colorectal, etc. [2, 3, 4]. Nd:YAG lasers and diode lasers with a wavelength close to infrared light are mostly used in the treatments due to blood and tissues ability of photoresponse. The absorbed light can inhibit stimulation and deteriorates blood if not monitored based on the absorption level of the blood, the laser power, and exposure duration. This will aid to check the excessive temperature upsurge build-up in the blood. The optical and blood thermal properties resulted from characteristics of the laser device determined the distribution of temperature and the level of the induced changes in the blood or tissues $[4,5,6,7,8,9,10,11,12,13,14]$.

The specific absorption rate (SAR) quantified the amount of energy absorbed by the blood or tissue. It is expressed in Watts per kilogram of the blood weight $[5,6,9,10]$. The emitted laser radiations during medical practices are absorbed by the blood penetrating through the exposed cells and plasma, thereby producing heat around and within the exposed blood or tissue. There is a non-thermal effect which includes changes within the plasma contents and cellular levels. While the thermal effect is capable of causing harm by varying the blood temperature which results in cells and other blood constituents' damage if not taken into consideration $[4,8,12,15]$. The SAR serves as an optimisation model of the human blood or tissue from any adverse effect and the immediate surroundings. This is done by determining the amount of energy absorbed or dissipated by the blood, for reliable measurement and evaluation of safe limits for electromagnetic energy absorption by human blood $[6,7,8,13]$. Due to the use of headphones, there is a substantial amount of research in the literature that addressed the SAR assessment, although little or no document has been done in lasers. Collins and his group work on human head SAR determinations through magnetic resonance imaging (MRI), the authors estimated a head average SAR level range of 3.0 - 3.2 $\mathrm{W} / \mathrm{kg}$ [7]. It is unlikely for a significant temperature increase in the brain to occur as a result of perfusion but SAR limits in any $1 \mathrm{~g}$ of head tissue may be exceeded. The SAR values are relative to measured temperature changes which had a sharp increase in absorbed heat especially at the place near the ear skull due to constantly used of mobile phones $[4,7,8,14,15,16,17]$.

Since there are near to nothing that has been researched in the area of low-level laser for diabetes blood, it is pertinent to evaluate the SAR value relative to temperature variation for the

\footnotetext{
${ }^{*}$ Corresponding author tel. no: +2348067988338

Email addresses: gemanamsly@gmail .com (Sylvester J. Gemanam), terver.daniel@yahoo.co.uk (Terver Daniel)
}

diabetes blood during laser therapy. This is to enhance effective irradiation procedures during laser therapy and minimize what may negatively affect blood glucose levels. Diabetes mellitus is a complex and chronic disease and increasing health concern as the incidence increases worldwide [18]. It is responsible for the disruption of the lipid profile, especially increased susceptibility to lipid peroxidation, which results in increased atherosclerosis, a major complication of diabetes mellitus [3]. Therefore, comparing the diabetes blood SAR with that of the non-diabetes blood in terms of temperature variation, then its morphology and physiological analysis of the smear blood cells will aid with low-level laser biostimulation. This research sought to investigate appropriate SAR threshold values with respect to temperature variations for the optimal effect of low-level laser therapy in terms of physiological and morphological changes on the diabetes blood. Then do the same with non-diabetes human blood and compare to observe any difference in elucidating the effects of low-level laser biostimulation as a way to enhance diabetes mellitus practical non-medicinal therapy and prevention of some blood transfusion diseases.

\section{Experimental Materials and Methods}

A programmable automatic RLC analyser, model 4194A, adjustable frequency ranging from $40 \mathrm{~Hz}$ to $30 \mathrm{MHz}$ and oscillation level of $500 \mathrm{~V}$ was used to measure the capacitance, $C_{p}$ and dissipation factor $D_{f}$ with a delayed time of $0.05 \mathrm{sec}$. The impedance, $Z$ and conductance were calculated to determine the blood samples dielectric response using a designed blood cuvette as sample holder with two opposite pure copper electrodes connected to the impedance analyser [6, 7, 8, 9, 10, 19].

The dielectric permittivity was known to be expressed as a complex number

$$
\varepsilon^{*}(\omega)=\varepsilon^{\prime}(\omega)-i \varepsilon^{\prime \prime}(\omega)
$$

where $\varepsilon^{\prime}(\omega)$ is the real part known as relative permittivity or dielectric constant and $\varepsilon^{\prime \prime}(\omega)$ the imaginary part, represents the loss factor as functions in angular frequency, $\omega$. The dielectric constant $\varepsilon^{\prime}(\omega)$ was evaluated using:

$$
\varepsilon^{\prime}(\omega)=\frac{C_{p} d}{\varepsilon_{0} A}
$$

where, $d$ denotes the distance between the electrodes and $\mathrm{A}$ is the cross-sectional area of the electrode.

The imaginary part of the dielectric constant, $\varepsilon^{\prime \prime}$, was ascertained using the relations $[5,15,18,20]$ :

$$
\begin{aligned}
& \varepsilon^{\prime \prime}(\omega)=\varepsilon^{\prime} \tan \delta \\
& \sigma=\varepsilon_{r}^{\prime \prime} \omega \varepsilon_{0}
\end{aligned}
$$

then,

$$
S A R=\frac{\sigma|E|^{2}}{2 \rho}(W / k g)
$$

where $\delta$ is called the loss angle, $\tan \delta$ is called dielectric loss tangent and for low-loss dielectrics, $\delta$ is very small, $\sigma$ is the 
conductivity of the blood $(\mathrm{S} / \mathrm{m}), \varepsilon_{0}$ is the permittivity of free space $\left(8.854 \times 10^{-12} F / m\right), \omega=2 \pi f(f$ is the frequency in $\mathrm{Hz}), \rho$ is the density of the blood $\left(\mathrm{kg} / \mathrm{m}^{3}\right)$ and $\varepsilon_{r}^{\prime \prime}$ is the relative permittivity. $|E|^{2}$ is the electric field strength (field amplitude) $\left(\mathrm{V}^{2} / \mathrm{m}^{2}\right)$ of the wave (beam) $[9,16,17]$.

The wave energy is proportional to the square of the amplitude $\left(E^{2}\right)$, where the amplitude is proportional to pressure. But in electromagnetic waves, the amplitude is the maximum field strength of the electric and magnetic fields. Also, the intensity of an electromagnetic wave and the energy carried is proportional to $E^{2}$ and $B^{2}$. Therefore, for a continuous sinusoidal electromagnetic wave, the average intensity $I_{a v}$ is expressed as given below [5, 15],

$$
I_{a v}=\frac{c \varepsilon_{0} \mathrm{E}^{2}}{2}
$$

Equation (6) is known as the Poynting vector magnitude equation, and the irradiance $\left(I_{a v}\right)$ is relative to electric field squared $\left(E^{2}\right)$ given by

$$
E^{2}=\frac{2 I_{a v}}{c \varepsilon_{0}}
$$

where $c$ in the equation is the speed of light $3.0 \times 10^{8} \mathrm{~m} / \mathrm{s}$ and other symbols retain their usual meanings as explained above $[2,5,6,7,9,12]$.

\subsection{Research ethical approval and blood sample collection}

The research approval was given by the University clinic management and controls as well as Human Ethics approval from JEPeM USM, under study protocol code of USM /JePeM $/ 16060208$ before data were collected. The anticoagulant Ethylene Diamene Tetra Acetic acid (EDTA) treated samples of venous blood were collected from 64 patients (32 diabetic patients with average blood fast sugar level of $9.28 \mathrm{mmol} / \mathrm{L}$ and 32 non-diabetic patients without other blood related diseases). The sample patients' age ranges from 22 to 54 years (mean age of 36 years) were used in the study work. All samples were collected from adults with no serious medical history of illness or under medication for major diseases and non-pregnant women. Blood samples were collected from the Wellness Centre of Universiti Sains Malaysia (USM), Pulau Pinang Malaysia, observing all the necessary safety conditions. This was done through the prior consent of the patients. Each of the samples was divided into two which were used as control and radiated samples for this study. The blood morphology and physiology conditions of the two grouped samples were properly examined using optical microscopy connected to the desktop scanner.

\subsection{Samples stimulations and experimental calculations}

The obtained blood samples from 64 patients were properly stirred and pipettes into the designed cuvettes connected to impedance analyser for data, before and after irradiation. The irradiation was carried out by using a portable diode-pumped solid state laser of wavelength $532 \mathrm{~nm}$ at different output powers of 50,60,70, and $80 \mathrm{~mW}$. The power adjustment was done using an optical radiation power meter. The exposure duration was timed out for different intervals of 5, 10, 15, and 20 minutes for each of the laser power adjusted.

The above equations (1), (2), (3), (4), (5), (6), and (7) were used for the various calculations to ascertain the SAR values for both the diabetic and non-diabetic blood. The data for blood capacitance $\left(C_{p}\right)$ and dissipation factor $\left(D_{f}\right)$ was gotten within the frequency range of $40 \mathrm{~Hz}$ to $30 \mathrm{MHz}$ of the impedance analyser. This was carried out after calibration using a standard $100 \Omega$ resistor for the instrument load data measurement and phase compensation, within room temperature of $21^{\circ} \mathrm{C}$. Also the temperatures of the blood samples were maintained and taken at room temperature. This is because the acidity of blood in vitro varies to such an extent with temperature that for accurate determination of its $\mathrm{PH}$, the inconvenience of working with temperaturecontrolled apparatus it has been the practice to take measurements at room temperature and then make the appropriate corrections $[4,21]$. The data were taken as a function of different frequencies corresponding to dielectric response and energy deposited in the blood by the LLL irradiation within a different time duration.

\section{Results}

The research evaluated the diabetic blood specific absorption rate from blood-laser therapy (BLT) by $532 \mathrm{~nm}$ wavelength laser under observed laser parameters and sample properties. It is observed that an increase in SAR values has direct effects on temperature changes in the blood. However, there is no rapid temperature rise since the absorbed energies are used in breaking down the ions and molecular chains form by the free radicals as a course of photochemical reactions (catalysis) and biostimulation of the blood constituents [2, 17, 22]. The SAR values dropped sharply as the turn-off point is attained at blood saturation peak when there is no more energy absorption rather heat is given off to balance the system, then triggered the temperature to its highest points. The temperature build-up gradually as long as there is continuous irradiation therefore the blood temperature becomes excessively high and rather cause more damages to the diabetic blood. Table 1 showed blood properties and laser parameters used in the evaluation of the appropriate SAR optimal values for biostimulation of both bloods.

\subsection{The effect of blood temperature on diabetic blood SAR.}

The values of experimental results demonstrated the corresponding effects of the average maximum blood temperature and its specific absorption rate from different exposure power and durations. Within an average temperature range of $24.2 \leq$ $28.0^{\circ} \mathrm{C}$ the diabetic blood samples were examined to improve the health conditions of erythrocytes morphological structure positively after exposures as shown in Table 2. This occurred within a little temperature variation because the photochemical reactions generally do not result in a significant rise in temperature. Photochemical effects involved either a change in the course of biochemical reaction due to the presence of an electromagnetic field or photodecomposition due to high energy photons that rupture molecular bonds [23]. There is an 
Table 1. Blood and Laser parameters used for SAR evaluation of both blood samples

\begin{tabular}{|c|c|c|c|c|c|c|}
\hline \multicolumn{7}{|c|}{ Material properties/Laser parameters } \\
\hline $\begin{array}{l}\text { Laser } \\
\text { Power } \\
(\mathrm{mW})\end{array}$ & $\begin{array}{l}\text { Exposure } \\
\text { duration } \\
\text { (mins) }\end{array}$ & $\begin{array}{l}\text { Calculated } \\
\text { Av. Blood } \\
\text { density }\left(\mathrm{kg} / \mathrm{m}^{3}\right)\end{array}$ & $\begin{array}{l}\text { Av. } \\
\text { Initial } \\
\text { temp. } \\
\left({ }^{\circ} \mathrm{C}\right)\end{array}$ & $\begin{array}{l}\text { Final } \\
\text { temp. } \\
\left({ }^{\circ} \mathrm{C}\right)\end{array}$ & $\begin{array}{l}\text { Laser spot } \\
\text { sectional } \\
\text { area }\left(m^{2}\right)\end{array}$ & $\begin{array}{l}\text { Laser } \\
\text { intensity } \\
\left(W / m^{2}\right)\end{array}$ \\
\hline 50 & $\begin{array}{l}5 \\
10 \\
15 \\
20\end{array}$ & 1020 & 23.2 & $\begin{array}{l}24.2 \\
27.4 \\
28.0 \\
29.2\end{array}$ & $1.26 \times 10^{-5}$ & 3968.25 \\
\hline 60 & $\begin{array}{l}5 \\
10 \\
15 \\
20\end{array}$ & 1020 & 23.1 & $\begin{array}{l}27.4 \\
27.7 \\
29.2 \\
30.4\end{array}$ & $1.26 \times 10^{-5}$ & 4761.91 \\
\hline 70 & $\begin{array}{l}5 \\
10 \\
15 \\
20\end{array}$ & 1020 & 23.2 & $\begin{array}{l}28.0 \\
29.2 \\
30.4 \\
30.6\end{array}$ & $1.26 \times 10^{-5}$ & 5555.56 \\
\hline 80 & $\begin{array}{l}5 \\
10 \\
15 \\
20\end{array}$ & 1020 & 23.2 & $\begin{array}{l}29.2 \\
30.5 \\
30.6 \\
32.9\end{array}$ & $1.26 \times 10^{-5}$ & 6349.21 \\
\hline
\end{tabular}

observed significant decreased of the immature cells to a slight increase in the erythrocytes count as a result of the reticulocytosis decreased (that's the decrease rate of the formed reticulocytes). The reticulocytes decreased served as the useful indicator of glycaemic been under control. The radiated blood shows a higher resistance as stimulated by absorbed laser photon light. The absorbed energy also lowers the blood coagulation system, improves the red blood cells into biconcave form and disc liked shape after stimulation forming a normocytic. Within this temperature range and corresponding values of diabetic blood absorption rate, there were noticeable optimal positive biostimulation effects on the irradiated samples that can be considered effective for low-level laser therapy. The resulting absorption rate values occurred within the range $0.140 \leq 0.695 \mathrm{~W} / \mathrm{Kg}$ excepts for exposure to $50 \mathrm{~mW}$ for 20 minutes, where the diabetic blood reaches the optimal saturation peak at 15 minutes of exposure and took a downward trend to $0.326 \mathrm{~W} / \mathrm{kg}$. This implies raising the blood temperature directly causes the heat transfer in the blood and the specific absorption rate to the saturation point thereafter occur a reverse effect on SAR. The radiated blood within this particular exposure has shown more cell damage and haemoglobin released in plasma and twice extracellular potassium than in non-irradiated blood (Tables 2, 3, and 4).

\subsection{Specific Absorption Rate (SAR) of diabetic and non-diabetic blood}

The experimental results here compared between the specific absorption rate (SAR) of non-diabetic to diabetic blood samples calculated via blood parameters: conductivity and blood density. The SAR values for both irradiated bloods (diabetes and non-diabetic) samples were observed to increase with increasing frequency untill attains saturated plateau before taking a descending direction. This increase reflects the biological impacts of blood-based thermal effects on key features.

The observed blood samples specific absorption rates are shown in Figures 1 and 2 below and some highlighted values in Tables 2 and 3 which shows the evaluated SAR values of the irradiated diabetic blood with the corresponding low-level laser biostimulation effects comparably higher than that of the nondiabetic blood counterparts. The morphological and physiological changes due to the biostimualtion effects of irradiation were captured through a microscope with a charged coupled device (CCD) camera connected to the computer operated by software as in Figures 3 and 4.

The higher SAR values of diabetic blood might be due to the high absorption capability rate of the high glucose present in the blood of diabetic patients $[19,24]$. This produces reactive oxygen species (ROS) derived from flavin, reduced nicoti- 
Table 2. The effect of blood temperature on the SAR of diabetic blood

\begin{tabular}{|c|c|c|c|c|c|c|c|c|}
\hline \multirow{2}{*}{$\begin{array}{l}\text { Duration/power } \\
(\mathrm{min})\end{array}$} & \multicolumn{2}{|l|}{$50 \mathrm{~mW}$} & \multicolumn{2}{|l|}{$60 \mathrm{~mW}$} & \multicolumn{2}{|l|}{$70 \mathrm{~mW}$} & \multicolumn{2}{|l|}{$80 \mathrm{~mW}$} \\
\hline & $\begin{array}{l}\text { SAR } \\
(\mathrm{W} / \mathrm{kg})\end{array}$ & $\begin{array}{l}\text { Av.Temp } \\
\operatorname{var}\left({ }^{\circ} \mathrm{C}\right) \\
\end{array}$ & $\begin{array}{l}\begin{array}{l}\text { SAR } \\
(\mathrm{W} / \mathrm{kg})\end{array} \\
\end{array}$ & $\begin{array}{l}\text { Av.Temp } \\
\operatorname{var}\left({ }^{\circ} \mathrm{C}\right) \\
\end{array}$ & $\begin{array}{l}\text { SAR } \\
(W / k g)\end{array}$ & $\begin{array}{l}\text { Av.Temp } \\
\operatorname{var}\left({ }^{\circ} \mathrm{C}\right) \\
\end{array}$ & $\begin{array}{l}\text { SAR } \\
(\mathrm{W} / \mathrm{kg})\end{array}$ & $\begin{array}{l}\text { Av.Temp } \\
\operatorname{var}\left({ }^{\circ} \mathrm{C}\right) \\
\end{array}$ \\
\hline 5 & 0.615 & 24.2 & 0.489 & 27.4 & 0.140 & 28.0 & 2.064 & 29.2 \\
\hline 10 & 0.647 & 27.4 & 0.695 & 27.9 & 1.666 & 29.2 & 2.412 & 30.5 \\
\hline 15 & 0.674 & 28.0 & 0.893 & 29.2 & 0.837 & 30.4 & 1.506 & 30.6 \\
\hline 20 & 1.195 & 29.2 & 0.326 & 30.4 & 2.060 & 30.6 & 1.552 & 32.9 \\
\hline
\end{tabular}

Table 3. Efficacy (optimization) of Normal patient's blood irradiated and SAR at characterized frequency of $40 \mathrm{~Hz}$

\begin{tabular}{|c|c|c|c|c|c|c|c|c|}
\hline Duration & $50 \mathrm{~mW}$ & & $60 \mathrm{~mW}$ & & $70 \mathrm{~mW}$ & & $80 \mathrm{~mW}$ & \\
\hline & $\begin{array}{l}\text { SAR } \\
(\mathrm{W} / \mathrm{kg})\end{array}$ & $\begin{array}{l}\text { Blood } \\
\text { Physiology }\end{array}$ & $\begin{array}{l}\text { SAR } \\
(\mathrm{W} / \mathrm{kg})\end{array}$ & $\begin{array}{l}\text { Blood } \\
\text { Physiology }\end{array}$ & $\begin{array}{l}\text { SAR } \\
(\mathrm{W} / \mathrm{kg})\end{array}$ & $\begin{array}{l}\text { Blood } \\
\text { Physiology }\end{array}$ & $\begin{array}{l}\text { SAR } \\
(\mathrm{W} / \mathrm{kg})\end{array}$ & $\begin{array}{l}\text { Blood } \\
\text { Physiology }\end{array}$ \\
\hline 5 & 0.173 & stimulate & 0.178 & stimulate & 0.791 & Bloat cells & 0.121 & Bloat cells \\
\hline 10 & 0.528 & stimulate & 0.390 & stimulate & 0.427 & Bloat cells & 0.443 & Bloat cells \\
\hline 15 & 1.417 & Bloat cells & 0.754 & Bloat cells & 0.576 & All crenate & 0.941 & $\begin{array}{l}\text { Lake \& } \\
\text { haemolysed }\end{array}$ \\
\hline 20 & 0.631 & crenate & 0.540 & crenate & 0.003 & $\begin{array}{l}\text { Lake \& } \\
\text { haemolysed }\end{array}$ & -0.130 & $\begin{array}{l}\text { Lake \& } \\
\text { haemolysed }\end{array}$ \\
\hline
\end{tabular}

Table 4. Efficacy /optimization of diabetic patient's blood irradiated and SAR at characterized frequency of $40 \mathrm{~Hz}$

\begin{tabular}{|c|c|c|c|c|c|c|c|c|}
\hline Duration & $50 \mathrm{~mW}$ & & $60 \mathrm{~mW}$ & & 70mW & & $80 \mathrm{~mW}$ & \\
\hline & $\begin{array}{l}\text { SAR } \\
(\mathrm{W} / \mathrm{kg})\end{array}$ & $\begin{array}{l}\text { Blood } \\
\text { Physiology }\end{array}$ & $\begin{array}{l}\text { SAR } \\
(\mathrm{W} / \mathrm{kg})\end{array}$ & $\begin{array}{l}\text { Blood } \\
\text { Physiology }\end{array}$ & $\begin{array}{l}\text { SAR } \\
(\mathrm{W} / \mathrm{kg})\end{array}$ & $\begin{array}{l}\text { Blood } \\
\text { Physiology }\end{array}$ & $\begin{array}{l}\text { SAR } \\
(\mathrm{W} / \mathrm{kg})\end{array}$ & $\begin{array}{l}\text { Blood } \\
\text { Physiology }\end{array}$ \\
\hline 5 & 0.615 & Stimulate & 0.489 & Stimulate & 0.140 & Stimulate & 2.064 & Bloat cells \\
\hline 10 & 0.647 & Stimulate & 0.695 & Stimulate & 1.666 & Bloat cells & 2.412 & All crenate \\
\hline 15 & 0.674 & Stimulate & 0.893 & $\begin{array}{l}\text { Bloat } \\
\text { cells }\end{array}$ & 0.837 & All crenate & 1.506 & $\begin{array}{l}\text { Lake \& } \\
\text { haemolysed }\end{array}$ \\
\hline 20 & 1.195 & $\begin{array}{l}\text { Bloat } \\
\text { cells }\end{array}$ & 0.326 & crenate & 2.060 & $\begin{array}{l}\text { Lake \& } \\
\text { haemolysed }\end{array}$ & 1.552 & $\begin{array}{l}\text { Lake \& } \\
\text { haemolysed }\end{array}$ \\
\hline
\end{tabular}

namide adenine dinucleotide phosphate (NADPH), and hemeprotein due to photosensitization of the cell chromophores. It is a key enabler for the various activation of signalling pathways, and the role of bio-stimulation in cells since laser light depends on them $[2,18,20,21,23]$ (Figures 1,2, 3 and 4). 


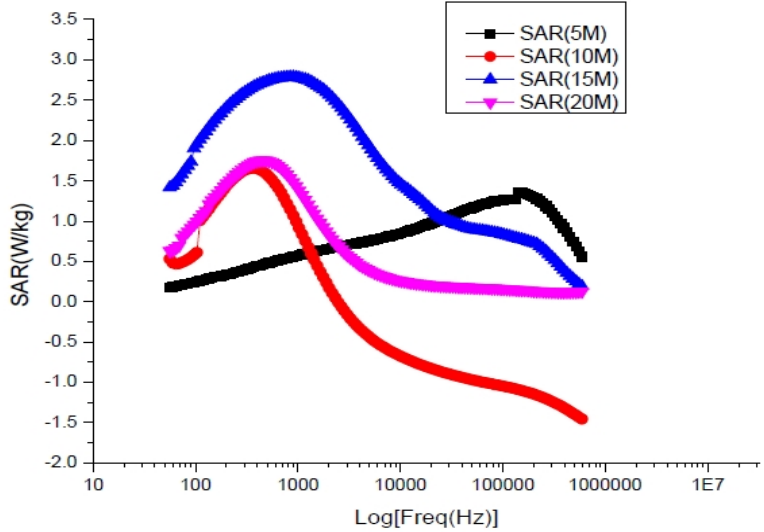

Figure 1. Frequency characteristics of SAR values of non-diabetic blood irradiated using a laser at an output power of $50 \mathrm{~mW}$ under different time duration.

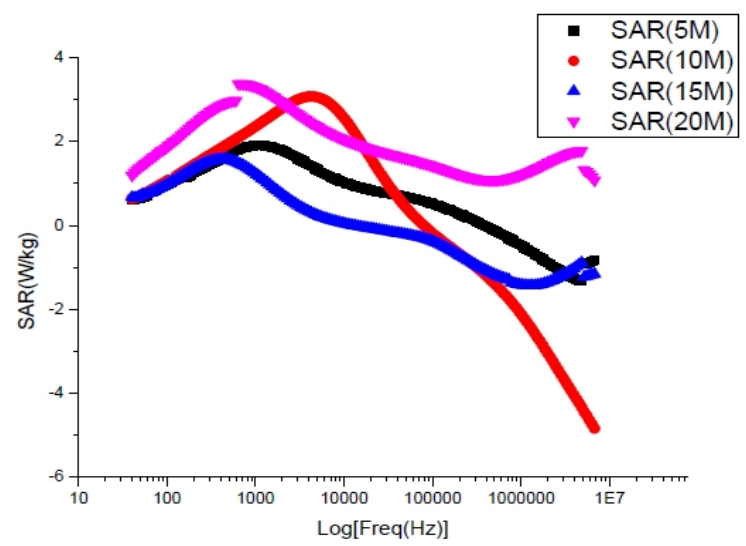

Figure 2. Graph of SAR values of diabetic blood frequency characterization irradiated using a laser at an output power of $50 \mathrm{~mW}$ under different time duration

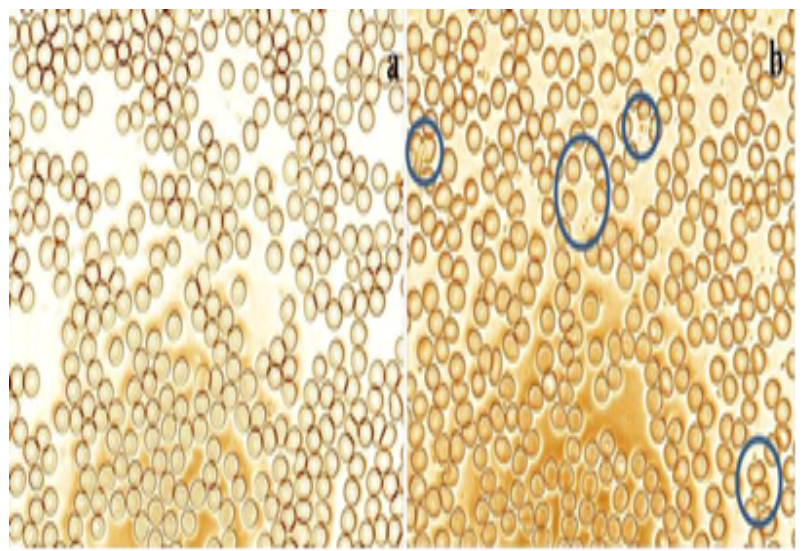

Figure 3. (a) Smeared control non-diabetic blood morphology and (b) diabetic blood morphology showing bloats RBCs, immature RBCs and some blast cells in blue circle. Magnifications 40X

\section{Discussions}

This research work was conducted to elucidate the low-level laser biostimulation effects as a way to enhance diabetes mellitus practical non-medicinal therapy and prevention of some
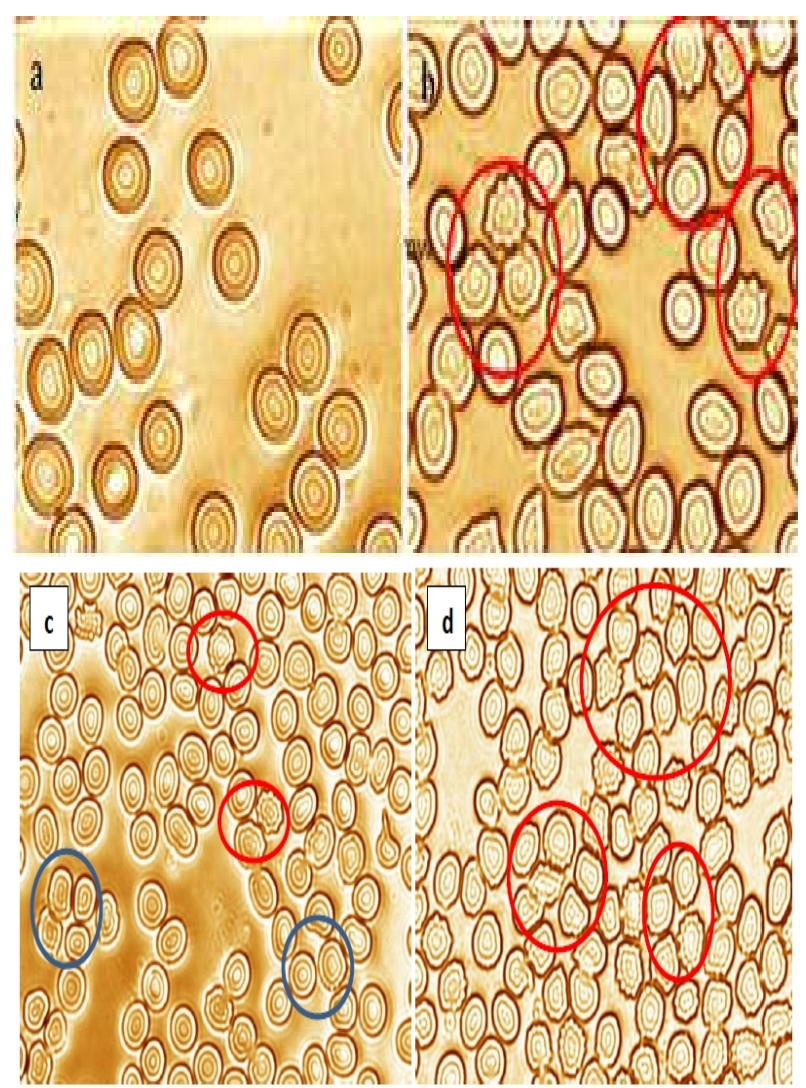

Figure 4. (a) Smeared diabetic blood irradiated within 10 and 15 minutes. (b) smeared diabetic blood stimulated $>15$ minutes durations showing cell crenation due to excessive irradiation at $50 \mathrm{~mW}$ power output. Magnifications 100X. (c) Smeared non-diabetic blood irradiated for 15 minutes showing bloat cells circled in blue and cells crenation in red circles. (d) smeared non-diabetic blood stimulated $>15$ minutes durations using laser at $50 \mathrm{~mW}$ power output showing cell crenation Magnifications 100X

blood transfusion diseases. This was observed with respect to the blood specific absorption rate relative to temperature variation. The research findings support the appropriate irradiation conditions for low-level laser therapy for diabetic mellitus optimising the efficacy of laser non-invasive treatment of diabetes mellitus.

The result findings in Figure 1, the irradiated blood identified as SAR (5M) reaches a maximum SAR value of $1.35 \mathrm{~W} / \mathrm{kg}$ at $100 \mathrm{kHz}$ frequency, also known as absorption peak after stimulation using a laser output power of $50 \mathrm{~mW}$ for a period of 5 minutes irradiation. At this point, the blood absorption rate yields the highest level which further frequency characterization and exposure often result in a sudden downward trend of lower SAR values. At high frequencies, the blood polarisation is not in the same phase with the applied energy as well as the blood SAR, therefore blood releases more heat than its absorption capacity. It is also noted that thermal effects apt to strongly occur beyond this peak. Thermal energy causes high blood temperatures associated with an imbalance between heat production and dissipation. Within this region, the blood is known to starts deteriorating at the point of becoming shrinking 
and crenation. The SAR peak result value of $1.65 \mathrm{~W} / \mathrm{kg}$ for 10 minutes of irradiated blood identified as SAR (10M) increased with increasing frequency and reached its plateau at $265 \mathrm{kHz}$ frequency mark. Excess heat was observed when the blood irradiated for 15 minutes; the SAR value was extremely high and reached a saturation point at $640 \mathrm{~Hz}$ with $2.79 \mathrm{~W} / \mathrm{kg}$. This even prevents the blood from being polarized at the high oscillation frequency. The detrimental deteriorating effect was observed for the human blood irradiated for 20 minutes since high exposure reversed the SAR trend downward right from the polarization stage, therefore, dropping its value instantly.

In Table 2, the findings show the stimulating effects after irradiating the blood of non-diabetic patients' samples, with different laser power and exposure duration to compare any occur effect with the diabetic blood. The morphology and blood physiology of the irradiation power of 50 and $60 \mathrm{~mW}$ for 5 and 10 minutes irradiation duration have no negative effects on results with slight moderate stimulations there are non-diabetes blood. The exposure for 15 minutes, effects on the irradiated blood are slightly excessive shown bloat and little crenate cells. The results obtained at all the laser powers for 20 minutes' blood stimulation period have lower SAR values while blood physiology was not satisfactory with bloat, crenate, and haemolysis effects (morphology and physiology conditions of the irradiated blood shown in Figure 4). This is because the absorption capacity of the blood is saturated and reflects the radiant heat from its absorption at these points resulting in crenation based on the laser intensity level as also shown in Table 3.

The results in Figure 2 presented the SAR values of diabetic blood under frequency characterizations of varying laser power output and exposure durations (morphology in Figure 3b). In the graphical representations of SAR for diabetic blood been irradiated at the power of $50 \mathrm{~mW}$ for 5 minutes indicated as SAR $(5 \mathrm{~m})$ increased with increasing frequency to saturation and absorption peak at the point of $1.906 \mathrm{~W} / \mathrm{kg}$. At a frequency of $1.1 \mathrm{kHz}$, the SAR values took a downward trend. Here, the blood molecules cannot regulate any higher frequency beyond and its rate of absorption retrogressed immediately. Before saturation point, exposed diabetic blood morphology observed to be maintained, although it is not sufficient to completely stimulate it. The radiation here does not help to renew the aging process of the plasma and cell membrane of diabetes mellitus. Diabetic blood exposed for 10 and $15 \mathrm{mins}$ (indicated as SAR $(10 \mathrm{M})$ and $\mathrm{SAR}(15 \mathrm{M})$ respectively) gives a better stimulating result when examined its morphological and physiological status. The blood temperatures within these exposure durations were moderate (average temperature range of $24.2 \leq 28.0{ }^{\circ} \mathrm{C}$ of the irradiated diabetic blood) and the irradiated blood shows a higher resistance, lower coagulation system, and improved the red blood cells to biconcave and disc liked shape that is normocytic as shown in Figure 4a. Also showed a slight increase in the erythrocytes count and decrease in the reticulocytes. There was no bloat appearance of the blood cells noticed after the exposures and showed an absorption rates range of $0.140 \leq 0.695 \mathrm{~W} / \mathrm{Kg}$. Within this average temperature range and corresponding values of the absorption rate there were noticeable optimal positive biostimulation effects on the irradiated samples that can be considered effective for the use of low-level lasers for treatment of diabetes mellitus. The blood reaches the maximum SAR at frequencies $4.3 \mathrm{kHz}$ and $398 \mathrm{~Hz}$, and the corresponding SAR values were 3.072 and $1.577 \mathrm{~W} / \mathrm{kg}$ respectively. Exposure of 20 minutes indicated as SAR (20M) did not produce good results due to excessive heating for long periods of time as observed in Figure 4b. And most diabetic blood cells became crenated due to shrinkage of cells that change the cell membrane. It inhibits the process of stimulation that can increase the resistance of cells that protect the $\mathrm{K}^{+}$ion efflux but accelerates the blood deterioration [12].

The microscopic examination of the blood morphology and physiological conditions in Figures 3 and 4 above reveals its stimulus on the basis of different biostimulation effects from SAR, temperature variation, and laser parameters. The examined smeared of diabetic blood irradiated using a $50 \mathrm{~mW}$ output laser power for exposure of less or equal to 5 minutes indicates that energy from the green laser is insufficient for erythrocyte to maintain its shape and correct defect. The effectiveness of diabetic blood stimulations was achieved with a $50 \mathrm{~mW}$ stimulated laser output power for a duration of 10 and 15 minutes. The smeared of exposed blood for more than 15 minutes produce unsatisfactory results. Where there are free intracellular $\mathrm{Ca}^{+2}$ concentrations that affect the efflux of $\mathrm{K}^{+}$ions $[12,16]$, it results in the crenation of the blood cells as in Figure 4. This is due to excess free radicals that caused changes in the molecular chemical structures as well as confirmation by altering H-bonds of membrane proteins $[1,18,19]$.

Table 4 summarized the stimulating effects of the irradiated diabetic blood based on the morphological/physiological conditions with different laser output power and of time periods with corresponding evaluated SARs at $40 \mathrm{~Hz}$ frequency. There are positive stimulation effects when lower laser output powers of $50 \mathrm{~mW}$ for 10 and 15 minutes then $60 \mathrm{~mW}$ for 5 and 10 minutes' duration were used for the irradiations. At an output power of $70 \mathrm{~mW}$, the positive stimulation effect lasted only 5 minutes. Although all other laser output power exposures with different duration results are unsatisfactory bloat cells and full of crenation.

\section{Conclusion}

We concluded from this research study that the LLLT stimulates the diabetic blood to effective cell rejuvenation showing positive biostimulation effects. The specific absorption rate (SAR) of blood served as a special tool to regulate and enhance the efficacy of the low-level laser blood therapy. This occurred at absorbance threshold SAR values of $0.140 \leq 0.695 \mathrm{~W} / \mathrm{kg}$ within an average temperature range of $24.2 \leq 28.0^{\circ} \mathrm{C}$ before saturation absorbance peak for the diabetic blood and the nondiabetic blood show positive stimulation within the SAR range of $0.173 \leq 0.528 \mathrm{~W} / \mathrm{kg}$ before turn-off peak absorbance point. The blood-laser therapy demonstrated a robust positive influence on the immune system cells and all blood exchange pro- 
cesses. These humongous effects help to improve not only the biostimulation as diabetic blood-laser therapy but indirectly capable in reduction of a certain number of transmission-associated graft-versus-host diseases (TA-GVHD) involved during blood transfusion. Whereas anything above the absorbance threshold of the SAR range inhibits the effectiveness of the laser therapy and causes more deteriorating effects on the diabetic blood. Contrary, at higher laser powers and time exposure, diabetic blood shows crenation due to profuse heating. This formed cell membrane shrinkage with an abnormal notching. The diabetic blood shows better stimulation within the low-level laser output powers of $50 \mathrm{~mW}$ for 10 and 15 minutes then $60 \mathrm{~mW}$ for 5 and 10-minutes duration. Therefore, LLLT has a positive blood stimulation effect by rejuvenating the diabetes blood cells and regulating the glucose negative effects within the blood as this reduces the concentration by breaking the bonds of its radicals.

The average blood density for both diabetic and non-diabetic patients have been calculated to be $1020 \mathrm{~kg} / \mathrm{m}^{3}$ as shown in Table 1 which agrees with the results obtained by [25] who concluded that the blood density is nearly equal to water density of $1000 \mathrm{~kg} / \mathrm{m}^{3}$.

Ethical Guideline: Blood samples from the patients used in the research were obtained from the Wellness Centre of Universiti Sains Malaysia (USM), Pulau Pinang, Malaysia. This was done through "prior consent of the patients" from the University clinic management and control as well as Human Ethics approval from JEPeM USM, under protocol code of USM / JePeM / 16060208 .

\section{References}

[1] D. J. Jordan, P. Mafi, R. Mafi, M. Malahias \& A. El. Gawad, "The Use of LASER and its Further Development in Varying Aspects of Surgery", Open Medicine Journal 3 (2016) 288.

[2] A. T. Zahra, "Investigating the Effects of Green Laser Irradiation on Red Blood Cells: Green Laser Blood Therapy", International Journal of Applied Research and Studies (IJARS) ISSN 3 (2014) 1.

[3] N. Suardi, M. Suhaimi, J. M. Mustafa, A. R. Hussein \& A. Zalila,"Effect of 460 and $532 \mathrm{~nm}$ Laser Light on the Erythrocyte Deformability of Anaemic Blood Samples", Journal of Physical Science 27 (2016) 85.

[4] M. A. Bhat \& V. Kumar, "Calculation of SAR and Measurement of Temperature Change of Human Head Due To The Mobile Phone Waves At Frequencies $900 \mathrm{MHz}$ and $1800 \mathrm{MHz}$ ", Advances in Physics Theories and Applications 16 (2013) 54.

[5] M. A. Bhat, "Health Hazardous of Specific Absorption Rate ( SAR ) of Mobile Phone Tower Waves", American Research Journal of Physics 5 (2016) 1.

[6] C. D. Bortner, F. M. Hughes, J. A. Cidlowski \& N. Carolina, "A Primary Role for $\mathrm{K}^{+}$and $\mathrm{Na}^{+}$Efflux in the Activation of Apoptosis", Journal of Biological Chemistry 272 (1997) 32436.
[7] C. M. Collins, W. Liu, J. Wang, R. Gruetter, J. T. Vaughan, K. Ugurbil, \& M. B. Smith, "Temperature and SAR Calculations for a Human Head Within Volume and Surface Coils at 64 and $300 \mathrm{MHz}$ ", Journal of Magnetic Resonance Imaging 656 (2004) 650.

[8] H. B. Cotler, R. T. Chow, M. R. Hamblin, J. Carroll \& M. G. Hospital, "HHS Public Access", MOJ Orthop Rheumatol 2 (2016) 1.

[9] J. P. Farkas, J. E. Hoopman \& J. M. Kenkel, "Five Parameters You Must Understand to Master Control of Your Laser / Light-Based Devices" Aesthetic Surgery Journal, 33 (2013) 1059.

[10] C. Kelemen, S. Chien \& G. M. Artmann, "Temperature Transition of Human Hemoglobin at Body Temperature?: Effects of Calcium", Biophysical Journal 80 (2001) 2622.

[11] V. Kumar, M. Ahmad \& A. K. Sharma, "Harmful effects of mobile phone waves on blood tissues of the human body", Eartern Journal of Medicine 15 (2010) 80.

[12] G. Litscher \& D. Litscher, "A Laser Watch for Simultaneous Laser Blood Irradiation and Laser Acupuncture at the Wrist", Integrative Medicine International Journal, 3 (2016) 75.

[13] A. A. Meesters, A. M. Nieboer, S. Kezic, M. A. Rie \& A. Wolkerstorfer, "Parameters in Fractional Laser Assisted Delivery of Topical Anesthetics?: Role of Laser Type and Laser Settings", Lasers in Surgery and Medicine, 8 (2018) 813.

[14] V. Mikhaylov, "The use of Intravenous Laser Blood Irradiation ( ILBI ) at 630-640 nm to prevent vascular diseases", Laser Therapy 24 (2015) 15.

[15] J. P. Matthias \& G. W. Andrew, "Safety of Ultra-High Field MRI: What are the Specific Risks?", Current Radiology Reports 2 (2013) 60.

[16] S. J. Gemanam, N. Suardi, S. Mokmeli \& I. Mustafa, "Evaluation of the Proper Level of Specific Absorption rate of Human Blood for 532 nm Laser in Blood Low-level Laser Therapy", Laser Physics 30 (2020) 035601.

[17] G. P. Kenny, R. J. Sigal \& R. McGinn, "Body Temperature Regulation in Diabetes", Temperature" 3 (2016) 119.

[18] M. Soheila, M. Daemi, Z. A. Shirazi, F. A. Shirazi, et al, "Evaluating the efficiency of low level laser therapy (LLLT) in combination with intravenous laser therapy (IVL) on diabetic foot ulcer, added to conventional therapy", Journal of Lasers in Medical Sciences 1 (2010) 8.

[19] G. O. Adam, B. Y. Park, K. M. Choi, H. S. Kang, \& G. B. Kim, "Effects of Ultraviolet Blood irradiation in a Diabetes Rabbit Model", Journal of Diabetes and Obesity 3 (2016) 1.

[20] T. Sowers, D. Vanderlaan, A. Karpiouk, E. M. Donnelly, E. Smith \& S. Emelianov, "Laser Threshold and Cell Damage Mechanism for Intravascular Photoacoustic Imaging", Lasers in Surgery and Medicine 15 (2018) 446.

[21] G. A. Zalesskaya, E. G. Sambor \& A. V. Kuchinskii, "Effect of intravenous laser irradiation on the molecular structure of blood and blood components", Journal of Applied Spectroscopy 73 (2006) 115.

[22] D. Ravelli, S. Protti \& A. Albini, "Energy and molecules from photochemical / photocatalytic reactions. An overview", Molecules 20 (2015) 1527.

[23] "Guidelines for Prevention of Transfusion-associated Graft-versus-host disease (TA-GVHD)", Australian and New Zealand Society of Blood Transfusion Ltd., (2011).

[24] O. S. Desouky, "Rheological and Electrical Behavior of Erythrocytes in Patients with Diabetes Mellitus", Romanian J. Biophysics, 19 (2009) 239.

[25] D. J. Vitello, R. M. Ripper, M. R. Fettiplace, G. L. Weinberg, \& J. M. Vitello, "Blood Density Is Nearly Equal to Water Density: A Validation Study of the Gravimetric Method of Measuring Intraoperative Blood Loss", Journal of Veterinary Medicine 2015 (2015) 152730. 